Original Research Paper

\title{
Smart Charger Based on IoT Concept
}

\section{Muhamad Hilmi Husin ${ }^{1}$, Irfan Danial Hisham ${ }^{1}$}

${ }^{1}$ Department of Computing, Faculty of Arts, Computing and Creative Industry, Universiti Pendidikan Sultan Idris, Malaysia.

Article History

Received:

04.03.2019

Revised:

27.04.2019

Accepted:

05.06.2019

*Corresponding Author: Muhamad Hilmi bin Husin Email:

hilmihusin1999@gmail.com
Abstract: This research develops Arduino based smart charging controlling. The aim is to develop a charging that can be controlled by setting the charger in a specific time. Therefore, the problem of overcharging will be anticipated. This research using the AA type of rechargeable battery, Nickel-Metal Hydride (NiMH). $\mathrm{C}++$ is being used for the Arduino. Arduino was chosen for this research because the Arduino boards are able to read inputs - light on a sensor or finger on a button - and turn it into output by activating a motor, turning on an LED, publishing something online. The result of this research is it has succeeded in creating the smart charger that can ensure the safety of the battery by controlling the amount of time in the charging process. The charging will be stopped if the time has reached the limit or if the temperature is high. Indeed, the research will inform the user whether the battery has been full charge or not.

Keywords: Smart Charger, Arduino, Phone Charger, Battery Charger. 


\section{Introduction}

The use of smart phone has been increased and it leads to the importance of charging. When charging a phone, it takes several hours by pluging. However, most of the people has accidentally overcharged their phone at least once in a lifetime. The burden of charging experience on users indeed a major problem when using a smart phone or other electronic devices [1]. Thus, the underline of the research was based on this observation. Some research has been done related to Smart Charger, one of them is a research named Navjeet Kumar [2] that develop smart charger using ESP8266 for the Internet of Things devices platform.

This research utilizes Arduino based module to develop smart charger. The Arduino was introduced in 2005 and it was designed to provide a low cost and easy way for professionals, students, or hobbyists to create devices that interact with their environment using sensors and acurators [3]. Arduino based Smartphone Charging Controller can help people to ease their charging system. For example, nowadays people are often lazy to control their charging phone system as the impact that people let their phone charging overtime [4]. This habit can decrease the life of the battery or even can cause harm for the owner itself because overcharge will cause the risk of explosion of the battery phone. By using Arduino based Smartphone Charging Controller, it can save the environment by reducing the use of electricity. Moreover, this research will help people to estimate their time to charge the phone and it will prevent harm of any accidents that cause from overcharging activity.

Through this research, it will help people that are too busy to charge their battery or don't have time to control their charging system manually [5]. By develop smart charger, it will ease the user by only controlling the charger using the rotary encoder. Also, this research can help to save electricity and save money for people that usually overcharge their phone. Arduino based Smartphone Charging Controller was created to ease the people in estimating their time of charge and to prevent the explosion of battery. Therefore, this research can save the life of battery and even save the electricity and money.

Arduino based Smartphone Charging Controller will enable the user to control the amount of time for a smartphone to charge its battery. For example, you have set the charging time for 2 hours (maybe based on the previous observation or by mathematical calculations). The power to the charger is turned on with the help of a relay and the timer begins. After your phone is being charged for 2 hours long, the relay will be turned off as well as the power supply of charger will be cut off automatically.

The objective of the research are; it can be help full to control the charging time once the time is set up; it is safer for the battery and your smartphone because it prevents your phone from overcharged; this research is useful for people who tend to charge the phone during night time or those who often forget that they plugged in the phone to the charge; give profit to the user.

\section{Methodology}

Prior this research, it has gathered the information through the internet and people about how long people charge their phone. By doing so, this research will able to identify the problem that occur when people charge their phone. It found that people often overcharge their phone especially during the night time as they start to charge their phone before going to bed. One of the most prominent issue that I found is when people charge their phone, they often forget to unplug their device when the battery has been full. This situation happens in almost every mobile phone (either a fancy smartphone or a simple feature phone) [6]. Indeed, it can harm the battery due to overheating and it can definitely make the battery life lowered. Through this research, it can control the time of the charging that you want and by doing so, it can save your battery life.

\section{Specification}

This research focuses on the most common type of AA rechargeable battery, Nickel-Metal Hydride (NiMH). The most convenient way to power portable electronics is by using rechargeable battries [7]. So, the battery that need to be charge is AA battery and all the components need to be installed in order to link it with the Arduino.

The code for this research is reasonably straight forward. There are variables at the top of the code that allow you to customize your charger by inputting the values of the battery capacity rating, and the exact resistance of your power resistor. There are also variables for the safety thresholds of the charger. The maximum allowable voltage of the battery is set to 1.6 volts. The maximum temperature 
of the battery is set to 35 degrees Celsius. The maximum charge time is set to 13 hours. If any of these safety thresholds is exceeded, the charger is turned off.

In the body of the code, will observe that system constantly measures the voltages of the terminal of the power resistor. This is used to calculate both the terminal voltage of the battery and the current flowing into the battery. This current is compared to the target current which is set to $\mathrm{C} / 10$. If the calculated current is different from the target current by more than $10 \mathrm{~mA}$, the system automatically adjusts the output to correct it.

The Arduino uses the serial monitor tool to display all the current data. If want to use monitor the performance of your charger, it can connect the Arduino to the USB port on your computer, but this is not necessary as the Arduino is powered by the $5 \mathrm{~V}$ power supply of the charger.

\subsection{Smart Arduino Phone Charger}

The main concept behind the Arduino based Smartphone Charging Controller is very simple. Set the time for which you wish to charge your mobile phone. Once the time is reached, turn off the power supply to the charger. For example, you have set the charging time as 2 hours (maybe based on the previous observation or by mathematical calculations). The power to the charger is turned on with the help of a relay and the timer begins. Your mobile phone gets charged for the next two hours and when the countdown is reached to the 2-hour mark, the relay is turned off and as a result, the power supply to the charger is also cutoff.

\subsection{Smart Battery Charger}

The circuit design for this charger is a basic Arduino controlled power supply. The circuit is powered by a 5-volt regulated voltage source such as an AC adapter or an ATX computer power supply.

Most USB ports would not appropriate for this research because of the current limitations. The $5 \mathrm{~V}$ source charges the battery through a $10 \mathrm{ohm}$ power resistor and a power MOSFET. The MOSFET sets how much current amount of power is allowed to flow into the battery [8]. The resistor is included as an easy way for monitoring the charger.

This is done by connecting each terminal to analog input pins on the Arduino and measuring the voltage on each side. The MOSFET is controlled by a PWM output pin on the Arduino. The pulses of the pulse width modulation signal are smoothed out into a steady voltage signal by a $1 \mathrm{M}$ resistor and a $1 \mu \mathrm{F}$ capacitor. This circuit allows the Arduino to monitor and control the current flowing into the battery.

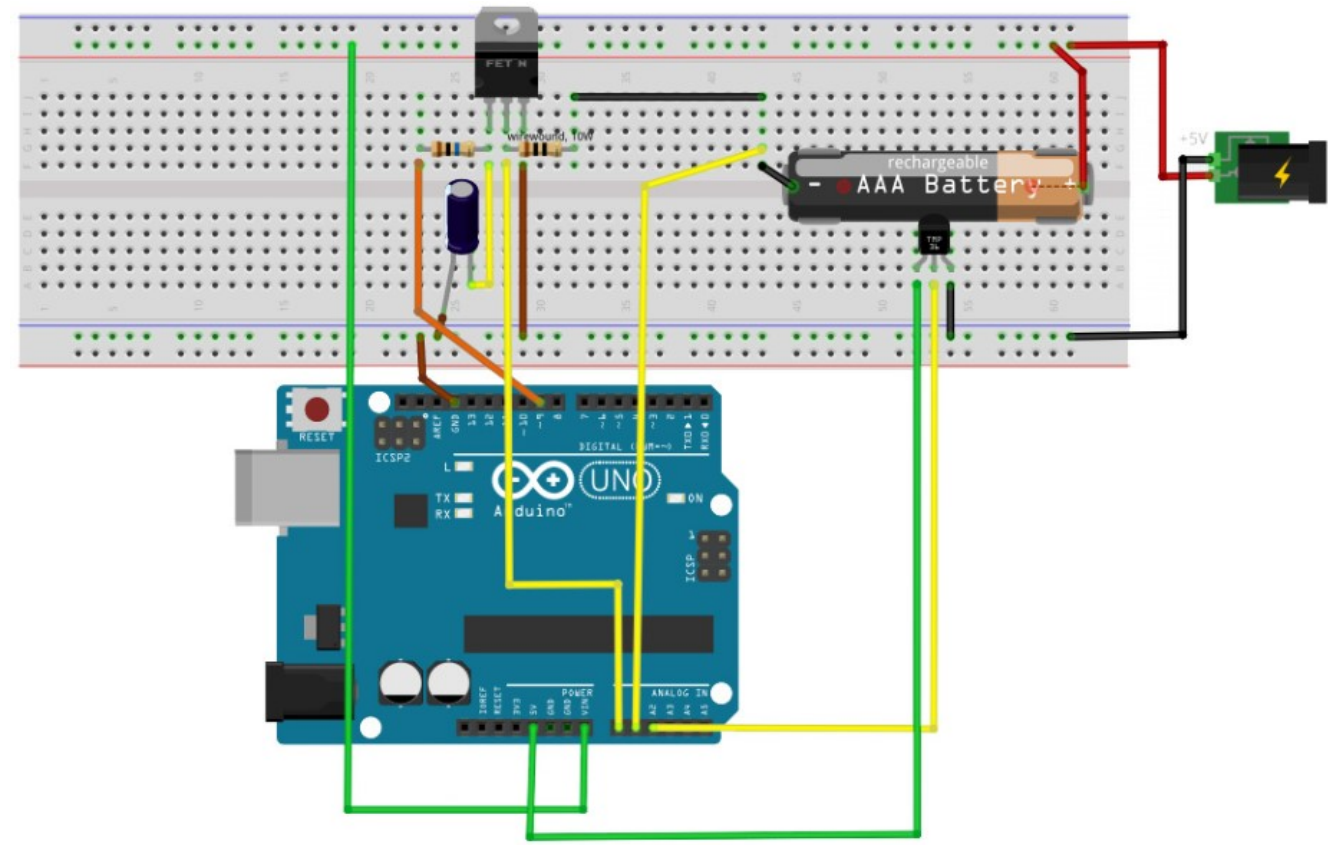

Figure 1. Smart Battery Charger by Smith [10] 


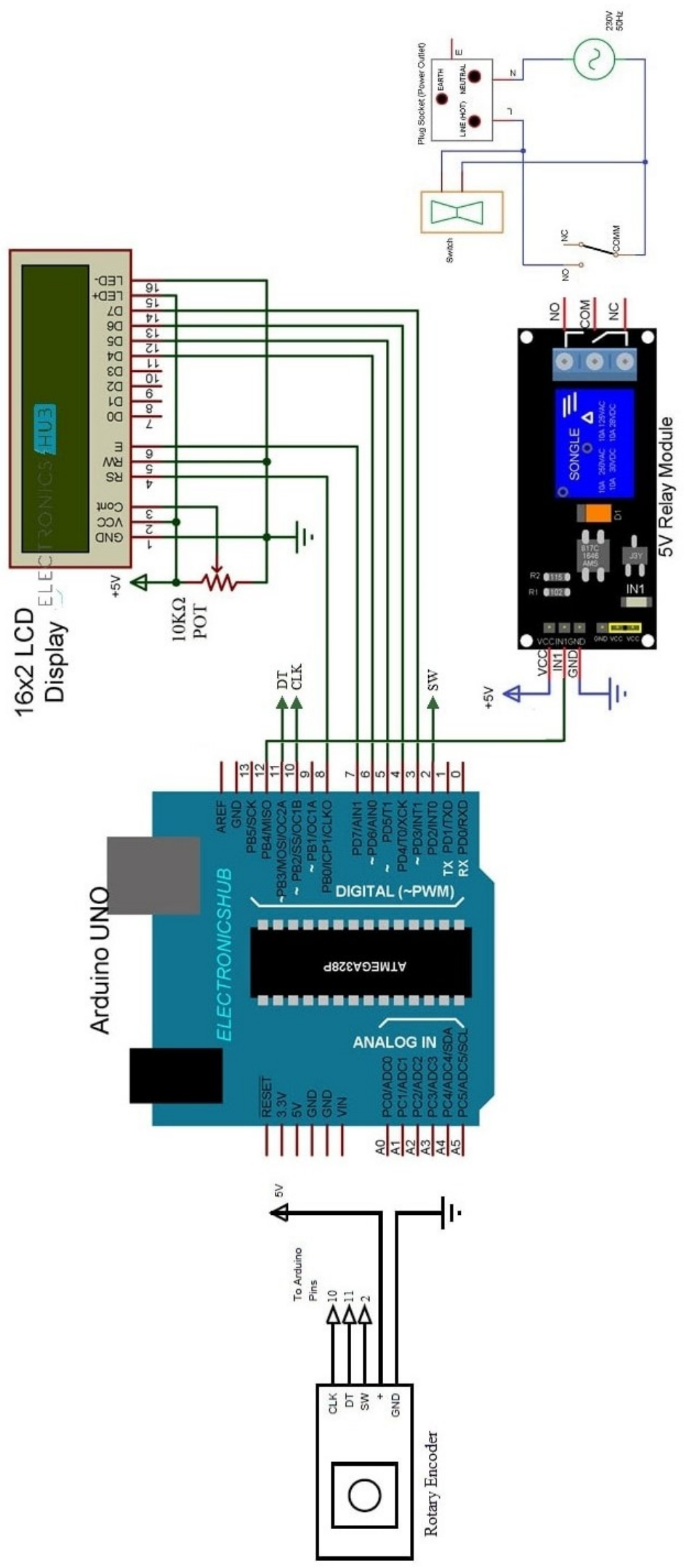

Figure 2. Smart Phone Charger 


\section{System Design}

First and foremost, the Arduino is using $\mathrm{C}++$ programming language that is an open-source electronics platform based on easy-to-use hardware and software [9] [10] [11]. Arduino boards are able to read inputs - light on a sensor or a finger on a button - and turn it into an output - activating a motor, turning on an LED, publishing something online. Arduino can display voltage and status of the battery [12] [13] [14] [15]. So, this research is using arduino to make the research success.

Furthermore, the research for smart phone charger is in progress and not fully completed so that the writer did the smart battery charger for the backup plan because smart battery charger is using the same method and have many related to many thing to smart phone charge even can be make the research more advanced

For future research, the research and experiment on making the smart phone charger with learning through the smart battery charger is needed and the writer will study more about smart battery charger so the research is more advanced and can be upgraded in a more advance form.

\section{Testing}

For the research it will be tested the time of the battery to be charged. Result shown in Table 1.

Table 1 . Time of the battery to be charged

\begin{tabular}{|c|c|}
\hline Minutes & Function \\
\hline 15 & Yes \\
\hline 25 & Yes \\
\hline 50 & Yes \\
\hline 60 & Yes \\
\hline
\end{tabular}

The temperature and voltage of the battery have been tested, the charging stopped when the temperature of the battery is high and the voltage of the battery is correct.

\section{Conclusion}

The strength of Smart Charger is can ease all the people and without worrying about their charger system. The Smart Charger can estimate the time of the charging easily. It can easily install with all the components and can easily ensure the ouput using the arduino serial monitor and just need to ensure that the coding in the arduino is right. This research can make people to estimate their charging time and can ensure the safety of the battery where the charging will be stopped if the temperature is high and in addition, this research can make the people know that the voltage of the battery and know whether the battery is full or not.

The weaknesses of the system are, it needs to use different component when the maximum voltage of the battery is high or low because it can cause and harm the battery so it is important to make sure and choose the right component when undergo this research. This research needs to know the right voltage to charge the battery and it may slow the charging of the battery because the components have its own limit. Thus, it can harm to complete this research it uses the power supply with high voltage.

In conclusion, this research gives many positive effects to our environment because of the best of technology. Future, this research will be applied in the Smart Phone Charger and it will lead to a more discovery of this research.

\section{References}

[1] Humavox, "Smart Parking and EV Charging," 2016. [Online]. Available: http://www.humavox. com/blog/wireless-charging-iot/. [Accessed: January 20, 2019].

[2] N. Kumar and K. M. S. Anusuya, "IoT Based Smart Charger: An ESP8266 Based Automatic Charger," in Proceedings of the International Conference on Big Data and Internet of Thing, London, United Kingdom, 2017, pp. 153-157.

[3] L. Louis, "Working Principle of Arduino and Using It as a Tool for Study and Research," International Journal of Control, Automation, Communication and System (IJCACS), vol. 1, no. $2,2016$. 
[4] C. Crawford, "People too lazy to control their charging," 2017. [Online]. Available: https://www.lifehack.org/484043/7-reasons-smartphones-make-you-lazy. [Accessed: January 20, 2019].

[5] B. Jones, "Overheating: Is It a Charger Issue or a Phone Issue," 2016. [Online]. Available: https://www.psafe.com/en/blog/overheating-charger-issue-phone-issue/. [Accessed: January 20, 2019].

[6] Ravi, "Arduino based smartphone charging controller," 2018. [Online]. Available: https://www. electronicshub.org/arduino-based-smartphone-charging-controller/. [Accessed: January 20, 2019].

[7] J. P. Smit, "Arduino Controlled Battery Charger," 2016. [Online]. Available: https://www. allaboutcircuits.com/projects/create-an-arduino-controlledbattery-charger/. [Accessed: January $18,2019]$.

[8] A. Faizan, "Battery Charger Using Arduino (DIY)," November 28, 2017. [Online]. Available: https://www.electronicshub.org/arduino-based-smartphone-charging-controller/. [Accessed: January 20, 2019].

[7] F. Hasan, "Arduino-Controlled 12V Battery Charger," 2018. [Online]. Available: https:// electronicsforu.com/electronics-projects/arduino-controlled-automatic-battery-charger.

[Accessed: January 20, 2019].

[8] J. P. Smith, "Controlled Battery Charger Diagram," 2016. [Online]. Available: https://www. allaboutcircuits.com/uploads/articles/arduino_battery_charger_diagram.jpg. [Accessed: January 26, 2019].

[9] M. S. Shah, S. H. Abbas, and S. A. Malik, "The Performance Evaluation of DGPS Data Correction Links in Dynamic Environments," Australian Journal of Basic and Applied Science, vol. 4, no. 6, pp. 1449-1458, 2010.

[10] J. M. Sáez, F. Escolano, and A. Peñalver, "First steps towards stereo- based 6DOF SLAM for the visually impaired," in IEEE Conf. on Computer Vision and Pattern Recognition (CVPR), San Diego, USA, 2005.

[11] V. Pradep, G. Medioni, and J. Weiland, "Robot Vision for the Visually impaired in CVAV110," in IEEE International Conference on Computer Vision and Pattern Recognition (CVPR), San Francisco, USA, 2010.

[12] S. Innet, and N. Ritnoom, "An Application of Infrared Sensors for Electronic White Stick," in International Symposium on Intelligent Signal Processing and Communication Systems," Bangkok, Thailand. 2008

[13] J. Na, "The blind interactive guide system using RFID based indoor positioning system," Lecture Notes in Computer Science, Springer Publications, vol. 4061, pp.1298-1305, 2006.

[14] T. H. Chang, and C. J. Ho, "iCane - A Partner for the Visually Impaired," Unpublished thesis, National Taiwan university, 2018.

[15] M. F. Saaid, I. Ismail, and M. Z. H. Noor, "Radio frequency identification walking stick (RFIWS): A device for the blind," in Proceedings of the IEEE 5th International Colloquium on Signal Processing \& Its Applications, Kuala Lumpur, Malaysia, pp. 250-253, 2009. 